\title{
DISCURSO DE AGRADECIMIENTO DEL SR. HUGO ZEPEDA BARRIOS, EN LA CEREMONIA DE ANJVERSARIO DEL COLEGIO DE ABOGADOS, ANO 1995
}

\author{
SEÑOR PRESIDENTE DEL COLEGIO DE ABOGADOS DE LA 4ª, REGION, \\ SEDE LA SERENA, DON MANUEL CORTES BARRIENTOS, AUTORIDADES, \\ COLEGAS ABOGADOS, ESTUDIANTES DE DERECHO, SEÑORES Y SEÑORAS.
}

Los años pasan y nublan la vista. pido por lo tanto disculpas por no leer personalmente estas líneas.

Para mi es motivo de singular satisfacción expresar al Sr. Presidente y a los colegas abogados mis más vivos sentimientos de gratitud por el inmerecido homenaje que hoy el Colegio de Abogados de la Región, me ha rendido.

El único mérito que puedo exhibir ante vosotros lo constituyen mis casi 67 años de pertenencia a vuestra orden.

Recibí mi título otorgado por la Excelentísima Corte Suprema el día 13 de noviembre de 1928 ingresando de inmediato al Colegio de Abogados presidido en alquel entonces por el eminente jurista Don Carlos Estévez Gazmuri con quien tuve el honor de compartir posteriormente labores cívicas en la Cámara de Diputados.

En La Serena presidía el Colegio de Abogados Don Fortunato Peralta Jeralgo.

No fui una persona extraña al foro, por cuanto fueron también mi padre, mi abuelo y mi tío abuelo Don Felix Alejandro Zepeda que se recibió siendo sacerdote.

Mi abuelo, Don Antonio Zepeda Alvarez, cuyo título de bachillerato en Derecho, lo firmó el insigne Andrés Bello, recibiendo su título de Abogado después ejerció ininterrumpidamente la profesión en Ovalle por espacio de 55 años.

Se caracterizó, cosa rara en un abogado, por ser muy parco en palabras la que también se traducía en sus escritos de muy corta extensión, por su claridad en la redacción, buena letra y planteamientos concisos.

También mi padre Don Gonzalo Zepeda Perry, ejerció por espacio de 25 años la profesión en Ovalle, distinto a mi abuelo. Tenía gran facilidad de expresión y un discurso brillante y elocuente, pero que no desmerecía su capacidad de síntesis en la exposición tanto en los alegatos como en los escritos. Además participó activamente en política desempeñando el cargo de Alcalde de la Ciudad de Ovalle y por dos periodos Diputado al Congreso Nacional. Terminó su carrera como Notario y Conservador de Bienes Raíces, de Coquimbo de 1923 hasta su fallecimiento en 1938.

Ejercí mi profesión en el puerto de Coquimbo, pero también en los Tribunales de La Serena y Ovalle. Recuerdo aún a los colegas de aquella época, casi 70 años, muchos de los cuales fundaron estirpes de abogados. Conocí después a sus hijos e incluso nietos. Nombraré sólo algunos: en Ovalle, como no recordar a Don Abdón Giménez quien ejerció la profesión por casi 70 años, conocido de todos vosotros. Don Blas Alvarez Jofré, Notario y Conservador de Bienes Raíces de Ovalle. Don Manuel Araya, Don Edmundo Contreras, Don Pedro Jorquera, Don Juan Antonio Mondaca, recibido de abogado ya maduro pero 
de mucho talento, Don Diego Peralta hijo del Presidente del Colegio de Abogado ya mencionado, Don Fortunato Peralta, Don Humberto Alvarez y Don Pedro Alfonso ambos de brillante trayectoria jurídica y política.

En La Serena, como no recordar a Alfredo Aguirre, en aquella época joven abogado. A Hernán Bonilla, David Cuellar, Ambrosio Muñoz, Don Manuel Antonio Pizarro, Luis Santana, a Don José Antonio Valdes y en especial a Gabriel González Videla y Jorge Salamanca Valdivia, grandes amigos, como asimismo amigos de mi padre y que lo fueron también mios, como Don Ernesto Peñafiel y Don Aurelio del Río, a su hijo Aurelio del Río Rondanelli.

En Coquimbo, a Osvaldo Palominos, Alejandro Giliberto, con quien me unió una gran amistad y Jorge Rojas Humeres, también recuerdo a Ministros de la Corte de La Serena y Jueces de mis primeros tiempos como abogado, cuando al alegar por primera vez a los 21 años de edad supe después del alegato que el sitial y mi escritorio frente al Tribunal había sido preparado epecialmente por el Presidente de la Corte Don Eulogio Robles gran amigo de mi padre, como no recordar al Fiscal Don Joaquín Ahumada al Relator Don Exequiel Zabala Bolados, y en Coquimbo a Don Martín Sotomayor, al Secretario Hugo Durán, y Don Urbano Marín y Don Octavio Montt y en Ovalle, como no recordar a Don Tomás Medina.

Debo tener un especial recuerdo por las personas con las cuales comparti mi estudio de abogado; Heriberto Pintó Argandoñã, Guillermo Sctanleburry y en forma especial al gran amigo Eugenio Medina Fernandez socio por más de 30 años, cuyo talento, acuciosidad jurídica y espíritu de trabajo siempre admire, 4 de los últimos años me correspondió compartir oficina con su hijo, don Roberto Medina Infante.

A la profesión de abogado y a los estudios de Derecho le debo que me haya proporcionado un lenguaje que me ha permitido a lo largo de muchos años desenvolverme en todo los planos de la existencia y en mi relaciones tanto sociales como políticas.

Podeis comprender cuantas viscisitudes, cuantas tareas en común me unen con muchos de vosotros aquí presente; también altos Magistrados a quienes conocí como Secretarios y como jueces de cabecera de departamentos, entre ellos a Don Federico Pizarro, a Don Héctor Careño, a Don Manuel Ruiz Aburto Don José Pavisic Don Alfredo Azancot Doña María Angélica Schneider, Don David Rojas y muchos otros.

Finalmente a quienes serán abogados en el futuro les deseo que obren con rectitud y diligencia en las labores jurídicas, siempre con espíritu de estudio, y así honrarán a nuestra profesión. Esto último lo digo porque ya en mis últimos años me ha correspondido el insigne agrado de ver formándose una Escuela de Derecho en el Puerto de Coquimbo, dependiente de la Universidad Católica del Norte, por lo que puedo esperar que el enorme campo profesional Minero, Oceánico, Agrícola de pequeños predios y comunidades de exportaciones frutales, todo tan típico de nuestra zona va a ser debidamente cubierto en un futuro no lejano por abogados formados aquí en la Región. Vayan, por lo tanto, mis felicitaciones en primer lugar la directora de esta Escuela de Derecho, Señora Luz María Reyes, cuyo trabajo tesonero y admirables condiciones han sido una valiosa contribución para cumplir estos logros, como asimismo, el cuerpo de profesores constituidos en su mayoria por profesionales de la Región que se han preparado para formar a los futuros abogados. 
Hugo Zepeda Barrios - Discurso de Agradecimiento, en Ceremonia de ...

Mil gracias por este homenaje que lo considero y acepto porque en mi modesta persona se aprecian los méritos de tantos otros más valiosos que ya no estan y que contribuyeron de manera eficaz a extender en estas latitudes el espíritu que anima la vigencia del Estado de Derecho, orgullo de la tradición Jurídica de Chilena. 